\title{
Towards Industrialisation in Tanzania: Drivers and Barriers to Green Manufacturing
}

\author{
Jeremiah W. Tumaini
}

Department of Business Administration, College of Business Education, Mbeya Campus, Tanzania j.tumaini@cbe.ac.tz

\section{ABSTRACT}

For the industrialization efforts to be fruitful and sustainable, they should be coupled with Green Manufacturing (GM) which simply implies clean manufacturing. This study analyses the drivers and barriers to GM in Tanzania. It specifically analyses the drivers and barriers to GM and ranks them for prioritisation. The study made the use of cross-sectional primary data which were collected using interviewer administered questionnaires from a random sample of 185 manufacturing firms in two purposively selected regions of Dodoma and Mwanza in Tanzania. In the analysis, the Binary Logistic regression was used to estimate the drivers and barriers to GM using the STATA software. The results showed that some of the significant drivers to green manufacturing include; firm size, firms resources, current legislation, incentives, and public pressure, The significant barriers included high short term costs, low customer demand, technological risk, lack of awareness and unclear benefits. It was also found that the highest ranked driver to GM was the firm size and the highest ranked barrier to GM was the short term costs. The study finally recommends that the relevant authorities should prioritize on the significant drivers and barriers to GM so that the move towards industrialisation in Tanzania can be more fruitful and sustainable.

Keywords: Industrialisation, Green Manufacturing, Barriers, Drivers, Tanzania

Cite this article as: Tumaini, J. W. (2021). Towards Industrialisation in Tanzania: Drivers and Barriers to Green Manufacturing. European Journal of Economics, 1(1), 41-50. https://doi.org/10.33422/eje. $\underline{\mathrm{v} 1 \mathrm{i} 1.7}$

\section{Introduction}

\subsection{Background of the Study}

Industrialisation has been one of the paths towards sustainable livelihoods in many parts of the world. The Industrial sector has been greatly contributing into the economies of most countries through its backward and forward linkages, (Gandhi et al, 2018). Broadly defined, the industrial sector in Tanzania accounts for around a quarter of Tanzania's Gross Domestic Product (GDP) with manufacturing dominating when measured in terms of industrial establishments and employment, (Mbele \& Kibanda, 2018). The Tanzania industrial sector makes up $26.4 \%$ of GDP which makes it the third behind Agriculture which accounts for $30.1 \%$ of GDP and the services sector, which contributes $43.5 \%$,(URT, 2018).

The country's efforts to stabilize the industrial sector can be traced back from the period after independence. This period started from 1961 to the current period where industrialisation has become a hot agenda during the fifth government. The first phase of industrialisation took place between 1961 and 1967 where the country was operating under the mixed economic system. In this period, the private sector dominated and more or less all manufacturing industries were inherited from the colonial powers. Major industrial activities were production of food/ beverages, textiles, and value adding processing to feed European industries, (Simon, Mwaseba, \& Juma, 2018). The second phase appeared between 1967 and 1985 in which the 
country's economy was under socialism. During this phase all the major means of production were under the government. It is in this period when the country experienced an historical growth in the manufacturing sector which has never been attained once again since then, (Wangwe et al., 2014). However, due to the macroeconomic instabilities resulting from both internal and external factors the growth could not be sustained longer, (Dinh, 2013; Wangwe et al., 2014). The third phase in the history of industrial development was between 1986 and 1995. This phase was marked by the structural adjustment programs under the Breton wood institutions. This phase brought back the role of the market economy in which the government entrusted the major means of production to the private sector. This period as well did not show much success since it coincided with the global trade liberalization and the domestic industries could not sustain the competition from cheap manufactured products from abroad, (Dinh, 2013; Silver, 2019; Simon et al., 2018).

After the three phases of industrialisation the country embarked into the new era of industrialisation. This era started with the establishment and implementation of the Sustainable Industrial Development Policy (SIDP) which is divided into three phases ranging from 1996 to 2020. This policy intended to transform the industrial sector into an industrial sector that could make human development and create jobs, make economic transformation for achieving a stable and sustainable economic growth, achieve environmental sustainability and equitable development, (URT, 1996). To support the implementation efforts of the SIDP, the country embarked into a vigorous political will with the agenda to become a middle income country by 2025 through industrialisation, (URT, 2011). This among other things will implies stabilizing the manufacturing sector to make it capable of creating jobs, meeting the internal and external demands and ultimately creating sustainable economic growth and equitable development.

However, not excluding Tanzania from the rest of the world, development in the manufacturing sector has been exerting much pressure on the environment as it entirely depends on it, (Kumar $\&$ Singh, 2014). This is because, to the manufacturing sector, the environment acts as a resource base for raw materials and a waste sink for the industrial wastes and finished products, (Perman, 2003). This has made the manufacturing sector to face the challenge to adhere to stringent environmental regulations due to the scarcity of natural resources and waste management issues, (Ariffin et al., 2015). Remarkably and recently, the government of Tanzania has prohibited the usage of plastic bags which has forced some manufacturing firms in the country to change their production technologies and some close their production due to their failure to abide to the regulation, (URT, 2019).

Recently the increased awareness about the impacts of resources depletion and environmental pollution has resulted into the adoption of a new paradigm in manufacturing known as Green Manufacturing (GM), (Niemann, 2016). GM is a concept which GM implies designing, manufacturing, delivering, and disposing products that produce minimum negative effect on environment and society and are economically viable, (Kumar \& Singh, 2014). The GM paradigm helps to minimize the environmental impact of manufacturing processes and ensures improvement in pollution control, reduction in consumption of natural resources and produces a green brand image, (Barzegar, Rasi, \& Niknamfar, 2018; Gandhi et al., 2018). Specifically, some of the ascertained benefits of implementing GM among others include; reducing waste through efficient use of energy and raw materials, enhancing productivity and increasing product yield through greater efficiency, increasing profitability and quality of products, reducing the risks of environmental accidents and avoiding regulatory compliance costs leading to insurance saving, (Mendoza-fong et al., 2019). Other studies which have confirmed the benefits of GM among others include:- Abdullah et al., 2015; Baines et al., 2013; Belekar, 2017.

Practicing GM among both small and large manufacturers has been influenced by a number of drivers and barriers. Some of the barriers commonly appearing in empirical literatures include:lack of awareness / information, technological risk, weak Legislation,(Kumar \& Singh, 2014; 
Mittal, Egede, Herrmann, \& Sangwan, 2013). Other barriers include low enforcement, uncertain future legislation, low public pressure, high short-term costs, uncertain benefits, low customer demand, low top management commitment and lack of organizational resources, (Ariffin et al., 2015; Gandhi et al., 2018; Kumar \& Singh, 2014; Niemann, 2016). On the side of the drivers for GM, the commonly identified drivers in empirical literatures include:- current legislation, future legislation, incentives, public pressure, peer pressure, cost savings, competitiveness, customer demand, supply chain pressure, top management commitment, public image, technology and organizational resources, (Barzegar et al., 2018; Kumar \& Singh, 2014; Mittal et al., 2013).

Almost all of the reviewed literatures have identified the need for establishing the drivers and Barriers to GM. Specifically, identifying the key drivers and barriers to GM helps organizations to strategically focus on them to reach to a higher level of competitiveness, (Mittal et al., 2013). Besides, it helps the decision/policy makers in government and industry to mitigate these barriers in an effective manner,(Kumar \& Singh, 2014).

However, as countries may differ in their industrial and environmental policies, the drivers and barriers to GM may likewise differ across countries. Moreover, the barriers and drivers may likewise differ across small and large manufacturers, (Ariffin et al., 2015). This sets the rationale for conducting this study in Tanzania which is dominated by small growing manufacturing sector,(Silver, 2019). It is also a good timing as the country is now embarking into the transformation of the economy to become a middle income country by 2025 through industrialisation. Ascertaining the drivers and barriers to GM will unveil the knowledge gap on what influences manufacturing firms in the implementation of green initiatives in Tanzania. This will obviously come with much benefit as shown in literature. The second gap that prompts more analysis is the degree of importance of these drivers/barriers to the decision/policy makers in government and industry. It is again worth prioritizing the drivers and barriers to bridge this gap so that this can aid in optimizing the usage of resources.

This study therefore this article is geared towards analysing the drivers and barriers to GM in Tanzania with the specific objectives of: - determining the drivers and barriers to GM, prioritizing the drivers to GM, prioritizing the drivers and barriers to GM.

\section{Research Methodology}

This study has followed both the qualitative and the quantitative research designs. The quantitative data were gathered to achieve the specific objectives of the study. For more clarity and precision, some qualitative data were also collected to supplement the findings from the quantitative data.

The main data used in this study were cross-sectional primary data which were obtained from a survey which was conducted covering 185 manufacturing firms which were the units of analysis for this study. The study area included two regions of Dodoma and Mwanza. Mwanza was included in the study because it is one of the leading 5 regions in Manufacturing in Tanzania,(URT, 2017). Dodoma was included because it is one of the fast growing regions in Tanzania, (Lilian Simon Mlay, Jeremiah Wilhelm Tumaini, Robert Galan Mashenene, 2017) The study population was the total number of manufacturing firms in the two regions which was 4,745,(URT, 2017; URT, 2019). The researcher used the systematic random sampling to select representative manufacturing firms from the list of all manufacturing firms in the study area. From each firm, the firm owner or a representative was selected to be a respondent on behalf of the firm. In the context of this study, it was assumed that the firm owner is the one most responsible for implementing the GM initiatives.

The sample size for this study was calculated (assuming 95\% confidence level) using the simplified formula for proportions,(Israel, 1992). The sample size obtained was 189 firms. 
A survey was conducted in August 2020 covering the sampled firms to solicit the information required for the study. Out of the expected sample 185/189 (97.9\%) firms could be surveyed. In the survey, structured questionnaires were used as the main tool for data collection. This questionnaire was comprised of questions intending to solicit both quantitative and qualitative responses from the respondents. In the field, the questionnaires were administered using the interviewer administered technique. This enumeration technique was chosen because it has the advantage of fusing the interview and the questionnaire tools for data collection. Where the questions are not clear, the enumerators had a room for clarifying the questions and / or asking a follow up question for clarity, (Lozano et al., 2016).

In order to achieve the study objectives the data obtained were analysed using a binary logistic regression model which estimated the drivers and barriers to GM. The dependent variable for the model was the firm's readiness to apply GM. The attributes considered in forming this variable were the readiness to apply GM in product design, process design, and manufacturing planning and control. This variable assumed the value of 1 for the averaged mean scores of the likert scale statements exceeding the median score of 2.5 or the value of 0 for the value of the averaged mean score below the median value of 2.5. The independent variables were the barriers and drivers to GM as identified in literature. The drivers included; firm size, firm age, availability of incentives, public pressure, cost saving, competitiveness, firms resources and the available legislations. Barriers included short term costs, low demand, technological risk, low commitment, lack of awareness, poor enforcement of laws and unclear benefits.

With the exception of firm's size and the firm's age which were continuous variables, all other variables including the dependent variable were dichotomous. The mean scores of the 5 points likert scale statements forming the variables were found and dichotomous variables were formed based on the criterion that any score exceeding the median score of 2.5 was given the value of 1 while the scores below 2.5 were given 0 for all dummy variables.

The binary logistic econometric model to estimate the drivers and barriers to GM was specified as seen in equation 1.

$$
L_{i}=\ln \left(\frac{P_{i}}{1-P_{i}}\right)=\beta_{0}+\beta_{1} X_{1}+\beta_{3} X_{2}+\cdots+\beta_{\mathrm{n}} X_{n}+\varepsilon_{i}
$$

$L_{i}$ is a notation for logistic regression. $P_{i}$ is the probability that a firm is ready to apply GM initiatives $\beta_{1} \ldots \ldots \beta_{n}$ are coefficients and $x_{1} \ldots \ldots x_{n}$ are independent or explanatory variables representing the drivers or barriers to GM.

A further analysis was also done to rank the significant drivers and barriers to GM. This was done by ranking the mean scores of the firm's opinions regarding the intensity of the drivers or barriers.

\section{Findings and Discussions}

\subsection{Descriptive Analysis}

\subsubsection{Sample Descriptive Characteristics}

The survey for this study was conducted in the two regions of Dodoma and Mwanza. Out of the surveyed regions, 98 firms could be surveyed in Mwanza while 87 firms from Dodoma were surveyed. All responses were completed successfully since the interviewer method was used in administering them. Out of all the respondents 39(21.2\%) were the CEOs of their organisations, 26(14.1\%) were managing directors 50(27.1\%) Executives and 70(37.6\%) were other categories of employees representing the owners of their organisations. Out of the surveyed firms, $1(0.54 \%)$ was a textile firm, 28(15.1\%) were from the chemical industry, 20(10.8\%) were from the Rubber/Plastic industry, $9(4.9 \%)$ were from the Machinery industry, $54(29.2 \%)$ were sunflower oil refineries, $1(0.54 \%)$ Steel/Iron, $33(38.8 \%)$ were from the food 
processing industry. Based on the number of employees in the firm, 11(6.0\%) of the surveyed firms were found to be large enterprises, 26(14.0\%) were medium enterprises, $100(54.1 \%)$ were small enterprises while the remaining 48(26.0\%) were micro enterprises. In the investigation of the export share of the firms, $26(14.0 \%)$ were partially producing for exports and the remaining $159(85.9 \%)$ were producing only for the domestic consumption. None was producing entirely for export purposes.

\subsubsection{Knowledge about Green Manufacturing}

The other important descriptive finding was about the knowledge on the concept of GM. It was found that $118(63.8 \%)$ of firms had very little or no knowledge on the concept of GM.

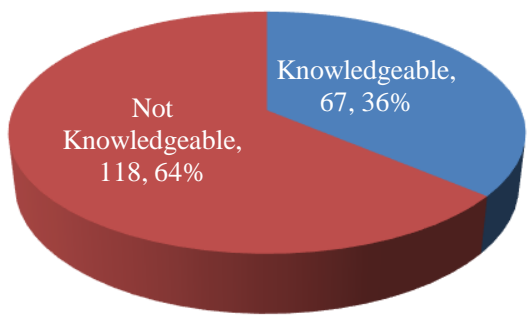

Figure 1. Knowledge about Green Manufacturing

\subsubsection{Readiness to apply Green Manufacturing}

After a simple description about the concept of GM to the respondents, they were then asked to show their readiness to apply the GM initiatives in their organisations. The 5 point Likert scale questions were asked in three main sections soliciting the readiness to apply GM. These included product design, process design, and manufacturing planning and control. The results were as presented in table 1.

Table 1.

Firms' Readiness to apply Green Manufacturing

\begin{tabular}{llc}
\hline S/N & Category & Mean score \\
\hline 1 & The firm is ready to move to green product design & 2.80 \\
2 & The firm is ready to apply green processes & 3.07 \\
3 & The firm is ready to practice green manufacturing planning and control & 2.75 \\
\hline
\end{tabular}

The results from the table show that the respondents were generally agreeing with all the statements soliciting their levels of agreement with the application of GM. This is because all the mean values were exceeding the median value of 2.5. However, the level of readiness is still low since all the mean scores are not much greater than the median score of 2.5.

\subsection{Inferential Statistics Analysis}

\subsubsection{Drivers for Green Manufacturing}

To estimate the drivers and barriers to GM, the binary logistic regression model in equation 1 was run. The results from the marginal effects after regression were as seen in table 2 .

Generally, from the results in table 2, it can quickly be seen that all the drivers had positive coefficients showing their positive relationship with the application of GM while all the barriers had negative coefficients showing their negative relationship with the application of GM.

From the table, the significant drivers to GM were: - firm size, incentives, public pressure, firms' resources and the available legislation. Same results were found by other studies like, (Ariffin et al., 2015; Kumar \& Singh, 2014; Mittal et al., 2013; Niemann, 2016) 
The size of the firm (Size) was strongly significant at $1 \%$ showing that as the size of the firm increases by one unit it increases the probability of the firm to be ready to practice GM by $0.25 \%$. This is likely because large firms have more resources and can invest in greener technologies as opposed to small firms.

Table 2.

Marginal Effects after Logistic Regression

\begin{tabular}{llc}
\hline Variable & Coefficient $(\mathbf{d y} / \mathbf{d x})$ & P - Value \\
\hline Size & $0.0025488^{* * *}$ & 0.006 \\
Age & -0.1052382 & 0.178 \\
Incentives & $0.2148488^{*}$ & 0.051 \\
Pressure & $0.1488832 * * *$ & 0.008 \\
Save costs & 0.3146765 & 0.127 \\
Competitiveness & 0.0576735 & 0.555 \\
Resources & $0.0490142 * *$ & 0.042 \\
Legislation & $0.3386084 * *$ & 0.032 \\
Costs & $-0.6476787 * * *$ & 0.004 \\
Demand & $-0.456734 * * *$ & 0.007 \\
Technology & $-0.5634825 * *$ & 0.034 \\
Commitment & -0.2356821 & 0.145 \\
Awareness & $-0.25674324 *$ & 0.073 \\
Enforcement & $-0.5678346^{* *}$ & 0.024 \\
Benefits & $-0.4356254 * *$ & 0.042 \\
\hline
\end{tabular}

Note: $* * *$ and $* * *$ indicate significance at $10 \%, 5 \%$ and $1 \%$ levels respectively

Availability of incentives (Incentives) to the GM applying firms was weakly significant at $10 \%$. This implies that a change from non-availability of incentives to the availability of incentives increases the probability of a firm to apply GM by $21.5 \%$ holding other variables at their means. This is likely because incentives to firms practicing GM encourage them to practice GM by reducing the costs associated with GM.

Public Pressure (Pressure) was found to be strongly significant at 1\% significance level. From this it can be inferred that a movement from the non-presence of public pressure to the presence of public pressure increases the probability of a firm to practice GM by $14.9 \%$ holding other variables at their means. This likely means that the increase in public pressure in terms of demand of suppliers, distributors, local communities, politicians, NGOs, media, insurance companies, banks influence the firms to apply GM.

Firm's resources (Resources) were significantly influencing the application of GM at 5\% significance level. A movement from the non-availability of resources for practicing GM to the availability of resources increases the probability of the firm to practice GM by $4.9 \%$ holding other variables at their means. Impliedly, this is likely because the availability of organizational resources such as skilled and motivated staff, healthy financial situation or performance measurements make firms more capable of applying GM

Available Legislation (Legislation) was found significantly determining the application of GM at 5\% significance level. Intuitively, a movement from non-availability of strict legislations to the availability of strict legislations increases the probability of the firm to apply GM by 33.9\% holding other variables at their means. This may be because strict legislations followed by strict enforcement compel manufacturing firms to abide to environmental standards.

\subsubsection{Barriers to Green Manufacturing}

Referring to table 2, the significant barriers to GM were: - Short term costs, low level of demand, technological problems, firm's awareness, poor enforcement, uncertain benefits. Similar studies which come out with the same results were (Ariffin et al., 2015; Gandhi et al., 2018; Kumar \& Singh, 2014; Mendoza-fong et al., 2019) 
Short term costs (Costs) were found to be significantly determining the application of GM at $1 \%$ significance level. A movement from the category of firms which do not perceive short term costs as barriers to GM to the ones which perceive short term costs as a barrier to GM, it decreases the probability of a firm to apply GM by $64.8 \%$ Holding other variable at their means. This is likely because the application of GM is accompanied by some short term costs which are entirely borne by the firms and thus discourage them in practicing GM.

Low customer demand (Demand) low customer demand was negatively and strongly determining the application of GM at $1 \%$ significance level. This implies that a movement from the firms with high customer demand for green products to the firms with low customer demand for green products decreases the probability of the firm to apply GM by $45.7 \%$. This is likely because firms with low customer demand for their products do not find it useful to apply GM.

Poor access to technology (Technology) had a negative significant influence on the application of GM. Its significance level was 5\%. This means that a movement from the category of firms with access to modern manufacturing technology to the ones with poor access to manufacturing technology decreases the probability of the firm to apply GM at $56.3 \%$ holding other variables at their means. This may likely come from the fact that poor technologies are not in favour of GM.

Lack of awareness (Awareness) about the concept of GM among firms could negatively and strongly determine the application of GM at $1 \%$ significance level. This means that, a movement from the category of firms with awareness about GM to the category of those who had no idea about GM decreases the probability for firms in applying GM. This is likely because lack of awareness about GM decreases the firms' awareness about its benefits and thus they do not see the point of practicing it.

Poor enforcement of the available rules and legislations (Enforcement) was negatively significant at $5 \%$. This means that a movement from the category of firms which perceived that the available legislations are well implemented to the category of firms which perceived that the available legislations are poorly implemented; it decreases the probability of firms in applying GM by $56.8 \%$. This is likely because firms which perceive the environmental legislations to be directly impacting them are more likely to comply with them.

Unclear benefits (Benefits) were found to be negatively influencing the application of GM by $5 \%$ significance level. The implication for this is that a movement from the firms which perceived that perceived GM to be having clear benefits to the firms which perceived no clear benefits, decreases the probability of applying GM by $43.6 \%$. This is likely because application of GM entails costs and firms would wish to maximize their profits though investing in ventures with clear benefits.

\subsection{Ranks of the Drivers and Barriers to Green Manufacturing}

To meet the second objective of the study the researcher estimated the mean scores of the significant drivers and barriers to GM. The ranks of the drivers were determined based on the score of the specific variables. The results were as shown in table 3 and 4.

Table 3.

Drivers to Green Manufacturing

\begin{tabular}{lcc}
\hline Driver & Mean score out of 5 & Rank \\
\hline Firm size & 4.0 & 1 \\
Firms resources & 4.0 & 1 \\
Current legislation & 3.6 & 3 \\
Incentives & 3.2 & 4 \\
Public pressure & 3.0 & 5 \\
\hline
\end{tabular}


Regarding the ranks of the drivers to GM, referring to table 4, the highest ranked driver to GM was the firm size. This is likely because large firms are likely to have more resources, better technologies, more awareness and are more sensitive to environmental regulations. The last ranked driver though also significant is the presence of public pressure and the other drivers were as can be seen on the table.

Table 4.

Barriers to Green Manufacturing

\begin{tabular}{lcc}
\hline Driver & Mean score out of 5 & Rank \\
\hline Short term costs & 4.4 & 1 \\
Low customer Demand & 3.9 & 2 \\
Lack of awareness & 3.9 & 2 \\
Low enforcement of laws & 3.4 & 4 \\
Unclear benefits & 3.2 & 5 \\
Poor technology & 2.8 & 6 \\
\hline
\end{tabular}

The barriers to GM were also ranked and they were presented as seen in table 4. The first ranked barrier was the short term costs. This is likely because, most firms are cost sensitive when it comes to the application of GM. The costs associated with the purchase and installation of GM technologies likely deters firms from applying GM. The last ranked barrier is lack of technology and the other barriers were as presented in the table.

\section{Conclusions and Policy Recommendations}

\subsection{Conclusions}

The application of GM is influenced by several factors including firm size, firm's resources, available environmental legislations, incentives given to firms and the public pressure. Any firm subjected to any of these factors is more likely to apply green GM.

Besides this, the firm's size and firms resources rank the first in influencing the application of GM. Bigger firms with more resources make the use of their resources to adopt greener technologies than smaller firms with fewer resources. Public pressure to apply GM takes the last priority in the drivers to GM.

Barriers to the application of GM based on the study area were short term costs, low customer demand, lack of awareness, low/poor enforcement of laws, unclear benefits associated with the application of GM and poor level of technology. It can therefore be concluded that any firm subjected to these barriers is less likely to apply GM.

Based on the ranks of the barriers to GM, sensitivity to the short term costs ranks the first in influencing the application of GM. Manufacturing firms find initial costs associated with the application of GM as the most serious barrier. Poor level of technology is the last prioritised barrier to GM.

\subsection{Policy Recommendations}

The identified significant drivers to the application of GM send a signal to policy makers on what they should focus on when designing and enforcing environmental policies. For better application of GM policy makers should focus on promoting the expansion of firms' resources, enforcing the available environmental regulations, providing incentives to better performing firms and educating the public about the need to use green products so that in turn the public may put more pressure on the manufacturers to produce green products.

The usage of resources to enhance the drivers of GM should be based on their degree of importance. More emphasis should be put on allowing small firms to expand their resource 
base so that they can afford greener technologies. However, other drivers should also be considered based on their rank / degree of importance to manufacturing firms.

Policy makers and implementers should also focus on the significant barriers to GM. It is worth recommending that the responsible authorities should consider subsidizing greener technologies to lower the short term costs for applying GM. This will also lower product prices and in turn increase customer demand. Education on the benefits of GM should also be provided and lastly innovations on greener technologies should be encouraged.

\section{Areas for Further Research}

This study focused only on the manufacturing sector specifically on the production stage. Future studies can consider researching on the whole green supply chain which may range from product design, production, distribution, consumption and disposal of waste products.

The coverage of the study included only two regions in the country. Future studies can consider expanding the coverage of the research so that better generalizations can be drawn from the findings.

\section{References}

Abdullah, M., Zailani, S., Iranmanesh, M., \& Jayaraman, K. (2015). Barriers to green innovation initiatives among manufacturers: the Malaysian case. Review of Managerial Science. https://doi.org/10.1007/s11846-015-0173-9

Amon Mbele \& Hafidh Kibanda. (2018). Recent progress towards industrialisation in Tanzania 1. Economic and Social Research Foundation.

Ariffin, R., Ghazilla, R., Sakundarini, N., Abdul-rashid, S. H., Ayub, N. S., Olugu, E. U., \& Musa, S. N. (2015). Drivers and barriers analysis for green manufacturing practices in Malaysian SMEs : A Preliminary Findings. Procedia CIRP, 26, 658-663. https://doi.org/ 10.1016/j.procir.2015.02.085

Baines, T., Brown, S., Benedettini, O., \& Ball, P. (2013). Examining green production and its role within the competitive strategy of manufacturers, 5(1), 53-87. https://doi.org/10.3926/ jiem.405

Barzegar, M., Rasi, R. E., \& Niknamfar, A. H. (2018). Analyzing the Drivers of Green Manufacturing Using an Analytic Network Process Method: A Case Study, 7(1), 61-83.

Belekar, A. M. (2017). Green manufacturing. International Research Journal of Engineering and Technology (IRJET), 4(7), 2667-2671.

Dinh, H. T. C. M. (2013). Light Manufacturing in Tanzania: A Reform Agenda for Job Creation and Prosperity. Directions in Development. Washington, DC: World Bank.

Gandhi, N. S., Thanki, S. J., \& Thakkar, J. J. (2018). Ranking of Drivers for Integrated LeanGreen Manufacturing for Indian Manufacturing SMEs Ranking of drivers for integrated lean-green manufacturing for Indian manufacturing SMEs. Journal of Cleaner Production, 171(October 2017), 675-689. https://doi.org/10.1016/j.jclepro.2017.10.041

Israel, G. D. (1992). Determining Sample Size 1. University of Florida, (November), 1-5.

Kumar, V., \& Singh, K. (2014). Prioritizing Barriers to Green Manufacturing : Environmental, Social and Economic Perspectives. Procedia CIRP, 17, 559-564. https://doi.org/10.1016/j. procir.2014.01.075

Lilian Simon Mlay, Jeremiah Wilhelm Tumaini, Robert Galan Mashenene, P. M. (2017). Agribusiness Investment Opportunities in Dodoma Region, Tanzania. Business Education 
Journal Volume, 1(IV).

Lozano, F., María, J., Lobos, Ramón, J., March, Eduardo Carrasco, M. B. B., \& Gonzálezporras, J. R. (2016). Self-administered versus interview-based questionnaires among patients with intermittent claudication : Do they give different results? A cross-sectional study Questionários autoadministrados versus administrados por entrevistador para pacientes com clau, 134(1), 63-69. https://doi.org/10.1590/1516-3180.2015.01733009

Mendoza-fong, J. R., Luis, J., Roberto, D., Jim, E., \& Blanco-fern, J. (2019). The Role of Green Attributes in Production Processes as Well as Their Impact on Operational , Commercial, and Economic Benefits. Sustainability, 11. https://doi.org/10.3390/su11051294

Mittal, V. K., Egede, P., Herrmann, C., \& Sangwan, K. S. (2013). Comparison of Drivers and Barriers to Green Manufacturing: A Case of India and Germany, 3-4. https://doi.org/ 10.1007/978-981-4451-48-2_118

Niemann, W. T. K. F. A. (2016). Drivers and barriers of green supply chain management implementation in the Mozambican manufacturing industry. Journal of Contemporary Management Volume 13 Drivers, 13, 977-1013.

Perman, R., Ma, Y., Mcgilvray, J., \& Common, M. (2003). Natural Resource and Environmental Economics (3rd ed.). Edinburgh Gate Harlow: Pearson Education Limited.

Silver, M. S. (2019). The Growth of Manufacturing Industry in Tanzania Westview Replica Editions. New York: Westview Press.

Simon, E., Mwaseba, S. L., \& Juma, M. S. (2018). Industrialisation in Tanzania: The Fate of Manufacturing Sector Lies upon Policies Implementations. International Journal of Business and Economics Research, 7 (3)(July), 71-78. https://doi.org/10.11648/j.ijber. 20180703.14

United Republic of Tanzania, (1996). Sustainable Industries Development Policy (SIDP). Ministry of Industry and Trade.

United Republic of Tanzania, (2017). Mwanza Region Investment Guide. Presidents Office Regional Administration and local Government Mwnaza Region.

United Republic of Tanzania, (2018). The Economic Survey 2017. Ministry of Finance and Planning.

United Republic of Tanzania, (2019a). Dodoma Region Investment Guide. Presidents Office Regional Administration and local Government Dodoma Region.

United Republic of Tanzania, (2019b). Environment Management: Prohibition of Plastic Carrier Bags. The United Republic of Tanzania.

URT, U. R. of T. (2011). Integrated Industrial Development Strategy 2025. Ministry of Industry and Trade.

Wangwe, S., Mmari, D., Aikaeli, J., Rutatina, N., Mboghoina, T., \& Kinyondo, A. (2014). WIDER Working Paper 2014/085 The performance of the manufacturing sector in Tanzania: Challenges and the way forward. World Institute for Development Economics Research Wider.Unu.Edu. https://doi.org/10.35188/unu-wider/2014/806-3 